\title{
Contribuições de práticas freirianas para a formação de professores/as: experiência de uma gestão escolar
}

\section{Contributions of Freire practices to teacher training: experience of school management}

\author{
Cosmerina de Souza de Carvalho ${ }^{1}$
}

Lilian Moreira $\mathrm{Cruz}^{2}$

\begin{abstract}
Resumo
Este artigo objetiva apresentar um relato de experiência de uma gestão escolar, que buscou pautar suas práticas nos princípios da pedagogia freiriana e contribuir para formação permanente dos/as docentes e discentes. Para tanto, adotamos uma pesquisa de abordagem qualitativa, do tipo descritiva e exploratória. Os dados mostram que a gestão incentivou os/as docentes a buscar a autoformação; a transformar o espaço escolar em um ambiente propício para aprendizagem; para isso, reelaboraram o projeto pedagógico da escola com a meta de diminuir o fracasso escolar, realizaram reuniões nos bairros onde os/as alunos/as residiam, realizaram visitas domiciliares; ministraram seminários internos para refletir sobre a prática pedagógica. Os resultados refletiram positivamente nas taxas de aprovação que subiram no $1^{\circ}, 2^{\circ}$ e $5^{\circ}$ ano para $100 \%$, do $3^{\circ}$ ano para $80 \%$ e do $4^{\circ}$ ano para $83,6 \%$. A taxa de evasão caiu para $0,3 \%$. O índice de atestados médicos e licenças médicas dos/as professores/as e funcionários/as diminuíram. Houve mudanças profundas no comportamento, assiduidade, pontualidade e rendimentos dos/as alunos/as. Contudo, não houve o apoio efetivo da secretaria municipal de Educação para realizar a reforma da escola e disponibilizar profissionais cuidadores/as. Em síntese, educação de qualidade se faz com o engajamento de todos/as.
\end{abstract}

Palavras-chave: Gestão democrática. Formação de professores. Educação críticoreflexiva.

\begin{abstract}
This article aims to present an experience report of a school management that sought to guide its practices on the principles of Freire's pedagogy and contribute to the continuing education of teachers and students. For that, we adopted a research with a qualitative approach, of a descriptive and exploratory type. Data show that management encouraged teachers to seek self-training; to transform the school space into an environment conducive to learning; for this, they redesigned the school's pedagogical project with the goal of reducing school failure, held home visit in the neighborhoods

\footnotetext{
${ }^{1}$ Especialista em Leitura e Produção Textual Aplicadas à Educação de Jovens e Adultos (IFBA), Pedagoga. Professora da Educação Básica do Município de Ilhéus-BA. E-mail: indias-sc@hotmail.com

2 Doutoranda em Educação pela Universidade Federal da Bahia (UFBA), Professora assistente da Universidade Estadual de Santa Cruz (UESC) - Brasil. Grupo de Estudos e Pesquisas em Educação Infantil/UESC. Integrante do Programa Coletivo Paulo Freire/UESC. E-mail: Imcruz@uesc.br
} 
where the students lived, carried out home visits; held internal seminars to reflect on pedagogical practice. The results reflected positively in the approval rates that rose in the 1st, 2 nd and 5 th year to $100 \%$, in the 3 rd year to $80 \%$ and in the 4 th year to $83.6 \%$. The dropout rate dropped to $0.3 \%$. The rate of medical certificates and medical leaves of teachers and staff decreased. There were profound changes in the behavior, attendance, punctuality and performance of students. However, there was no effective support from the municipal education department to carry out the reform of the school and provide professional caregivers. In short, quality education is done with the engagement of everyone.

Keywords: Democratic management. Teacher training. Critical-reflective education.

\section{Introdução}

Uma educação para a emancipação e autonomia do ser humano prioriza a formação permanente dos professores/as, a gestão democrática, (re)constrói o currículo, delimita políticas de combate ao fracasso escolar, ou seja, supera um modelo educacional reprodutivista, tecnicista, antidialógico e contra hegemônico. Entretanto, essas prioridades são planejadas e executadas na coletividade, a partir de um trabalho colaborativo entre todos/as envolvidos no processo educacional.

Foi pautado em uma ação dialógica e democrática que a secretaria Municipal de Educação de um município do interior da Bahia construiu um Projeto de Educação Inclusiva no final de 2014 e está em vigor até 2021. Durante os 7 (sete) anos de sua efetivação tem sido atualizado anualmente. Como qualquer município, atende muitas crianças, jovens e adolescentes públicos alvos da Educação Especial.

Isto posto, os/as professores/as vivem o dilema todo ano letivo quando em sua turma se deparam com alunos/as deficientes, com transtorno global do desenvolvimento ou com altas habilidades/superdotação. Muitos são os desafios para ofertar uma verdadeira inclusão nas escolas de educação básica; dentre eles, falta de formação continuada docente, infraestrutura adequada, recursos pedagógicos e humanos, entre outros. Diante deste contexto, o projeto de Educação Inclusiva foi implementado, primeiramente em três escolas da rede, nos seguintes segmentos: Educação Infantil, Ensino Fundamental anos iniciais e Ensino Fundamental anos finais.

Neste artigo, apresentamos a experiência da gestão de uma escola do ensino fundamental anos iniciais que abraçou o projeto Inclusivo e sedimentou as práticas nos princípios da pedagogia freiriana, e, por conseguinte, contribuiu para formação permanente dos/as docentes e discentes. Para escrever o artigo, adotamos uma pesquisa de abordagem qualitativa, do tipo descritiva e exploratória. Faz também parte desse tipo de pesquisa a constante interação da teoria com a prática dos pesquisadores/as, com o campo e sujeitos pesquisados (LUDKE; ANDRÉ, 1986). 
É válido salientar que, a gestão pesquisada executou o projeto a partir de um trabalho colaborativo, cujo objetivo foi contemplar as múltiplas dimensões da escola, o que exigiu compromisso e ética. Assim, elegeu uma gestão freiriana para gerir a escola, por entender que Paulo Freire foi um excelente modelo a ser seguido de democrata, com determinação e persistência, idealizando uma educação para a vida.

Paulo Freire dedicou a sua vida para criar possibilidades educacionais direcionadas às camadas menos favorecidas da sociedade, assim se preocupou em oferecer um modelo de educação contra hegemônico, ligado à luta pela emancipação e contra qualquer forma de dominação e exploração social. Em outras palavras, um modelo de educação voltado para uma práxis pedagógica-política, na busca pela formação libertária e emancipatória.

Inspirada em Paulo Freire, a gestão escolar utilizou o livro "Educação na cidade", que aborda uma experiência de gestão freiriana, na administração de Luiza Erundina, no município de São Paulo. O livro foi escrito em uma época de efervescência política, momento em que Paulo Freire assumiu a secretaria de educação da cidade de São Paulo, no período de 1989 a 1991.

Indubitavelmente, uma gestão escolar freiriana objetiva contribuir na formação permanente de professores/as e fundamenta-se na pedagogia da autonomia, na pedagogia da esperança e do diálogo. Incentiva os/as docentes a buscar a autoformação e o desejo de transformação do espaço escolar em um ambiente propício para aprendizagem de sujeitos populares críticos e conscientes. Além disso, busca contribuir para formação de estudantes participantes e políticos.

De posse das experiências freirianas, a gestora traçou as ações/metas objetivando possibilitar um ambiente que proporcionasse o desenvolvimento de professores/as, alunos/as, funcionários/as, familiares dos/as estudantes e comunidade em geral. Nesse ínterim, primeiramente elegeu a formação do/a professor/a como alvo principal das ações, posto que, o/a docente é um dos sujeitos fundamentais no processo da educação; segundamente, ocupou-se em analisar e construir metas para sanar problemas que impactam a aprendizagem dos/as estudantes, consequentemente, eliminar o fracasso escolar, assim buscou: - combater a violência na escola; - estabelecer parceria com as famílias; - trabalhar em prol das dificuldades e transtornos na aprendizagem; - extirpar práticas antidialógicas, segregadoras e discriminatórias dentro da escola, etc. Para tanto, necessitou estabelecer uma relação dialógica com as famílias.

A formação permanente de professores/as foi foco da gestão, pois ainda é considerada um desafio (IMBERNÓN, 2011). Como uma profissão que trabalha com o processo de ensinar e aprender, a docência requer estudo e muita reflexão sobre a prática pedagógica cotidiana. Nesse sentido, a escola se configura como excelente espaço para ofertar a formação permanente a partir de grupos de estudos e pesquisas, 
de compartilhamento de experiências da docência. Tudo isso só é possível, conforme ressalta Pimenta (2012), pela gestão democrática da educação.

Entretanto, uma gestão democrática da educação precisa ser sedimentada no diálogo, na escuta sensível, no movimento contínuo de se colocar no lugar do/a outro/a. Foi com essa perspectiva que a gestão abraçou o projeto de Educação Inclusiva, com os seguintes questionamentos: como provocar a construção de uma identidade docente crítico-reflexiva, autônoma, capaz de atuar no cenário contemporâneo educativo e não ficar refém dos déficits da educação, sendo meros executores/as de "tarefas" prontas? Como colaborar na construção dos saberes-fazeres docentes de sujeitos historicamente situados? É possível ofertar uma formação permanente dentro da escola, que acredita na educação como instrumento de luta política? Como fazer da escola um espaço aberto para o diálogo? Estas e outras questões foram fontes inspiradoras da gestão, buscando um caminho de ação a partir de uma interlocução com os princípios fundantes da pedagogia freiriana. Os resultados dessa gestão apresentamos e discutimos neste artigo, as páginas a seguir.

\section{Direito do/a professor/a à Formação permanente: reflexões freirianas}

Inegavelmente, um/a professor/a, no exercício de sua profissão, tem direito à formação permanente, ao passo que é na formação docente que ocorre a constituição profissional destes sujeitos (SCHÖN, 1997; TARDIF, 2002; PIMENTA; GHEDIN, 2002; CONTRERAS, 2002; ALARCÃO, 2003). Contudo, não se trata de qualquer tipo de formação, isto é, faz-se necessário um modelo de formação permanente que contribua para o desenvolvimento profissional docente. Este modelo parte da realidade que os/as docentes estão inseridos/as e faz investimentos qualitativos e quantitativos. Nessa perspectiva, a formação é contextualizada com o local de trabalho, apresenta uma proposta colaborativa para o/a docente se perceber e assumir a postura de um/a profissional pesquisador/a e atuante.

Sobre a Formação permanente docente, Freire ressalta:

Por isso é que, na formação permanente dos professores, o momento fundamental é o da reflexão crítica sobre a prática. É pensando criticamente a prática de hoje ou de ontem que se pode melhorar a próxima prática. O próprio discurso teórico, necessário à reflexão crítica, tem de ser de tal modo concreto que quase se confunda com a prática. O seu "distanciamento" epistemológico da prática enquanto objeto de sua análise, deve dela "aproximá-lo" ao máximo. Quanto melhor faça esta operação tanto mais inteligência ganha da prática em análise e maior comunicabilidade exerce em torno da superação da ingenuidade pela rigorosidade. Por outro lado, quanto mais me assumo como estou sendo e percebo a ou as razões de ser de porque estou sendo assim, mais me torno capaz de mudar, de promover-me, no caso, do estado de curiosidade ingênua para o de curiosidade epistemológica (FREIRE, 2007, p. 39). 
Paulo Freire (2007) deixou claro que é na formação permanente o lugar em que o/a professor/a aprende a olhar e analisar a sua própria prática com o ponto de vista crítico, a eleger as teorias que darão conta de suas necessidades profissionais. Posto isto, a formação permanente pode contribuir para o desenvolvimento profissional docente, visto que colabora na superação de situações-limites, na ampliação da compreensão da realidade/mundo, na transformação de formas de pensar e agir, na construção de novos saberes, na participação ativa e na construção da autonomia. É válido salientar que não se faz formação docente sem o diálogo, como também não se faz formação sem investimentos financeiros.

Deste modo, a formação precisa ser um caminho de possibilidades para o/a professor/a se aproximar da realidade concreta, por isso, os programas de formação docente devem ser contextualizados, os currículos devem levar em consideração os contextos das escolas, às necessidades de aprendizagens do/a professor/a. Contudo, é necessário dialogar com os/as professores/as e seu local de atuação profissional.

A universidade pode e deve contribuir na oferta dessa formação, a partir do tripé ensino, pesquisa e extensão. Foi com essa perspectiva que Paulo Freire assumiu a gestão da Secretaria Municipal de Educação de São Paulo no ano 1989 a 1991. Sua experiência é registrada no livro Educação na Cidade (FREIRE, 2001). Nessa obra, ele lança um olhar para a formação permanente de educadores/as e apresenta os resultados de sua atuação na gestão, ao desenvolver um trabalho colaborativo pautado na autonomia, em outras palavras, na participação ativa das universidades, dos/das docentes, diálogo constante, compartilhamento de saberes e experiências, relação teoria-prática e construção coletiva do conhecimento.

Freire (2007, p. 39) ressalta que: “[...] na formação permanente dos professores, o momento fundamental é o da reflexão crítica sobre a prática. É pensando criticamente a prática de hoje ou de ontem que se pode melhorar a próxima prática", assim o autor institui a educação popular como política pública e coloca a educação como prática da liberdade.

Tratando-se do Brasil, temos muito que avançar nesses fatores, posto que há uma política de formação docente defasada e condições precárias de trabalho, o que ficou evidente no contexto da gestão, foco de análise deste artigo. A gestora se deparou com o discurso da "falta" - falta infraestrutura adequada da escola; materiais pedagógicos de qualidade; práticas educativas inovadoras; tempo para planejamento das aulas; livros condizentes com a realidade dos/as alunos/as; formação permanente de professores/as; equipe de funcionários capacitados; pais e mães participativos; alunos/as motivados/as, comportados/as, alimentados/as e limpos/as; gestão democrática; currículo adequado; salários decentes, apoio da secretaria Municipal de Educação, entre outros.

Com o aprofundamento dessas lacunas na educação, Paulo Freire (2019; 2007; 2003) nos convida a refletir, a assumir compromisso profissional e nos posicionar 


\section{-Revista de Iniciação à Docência, v.6, n.2, 2021- Publicação: dezembro, 2021 - ISSN 2525-4332}

politicamente para resistir, porque diante de tudo isso, a formação permanente docente se torna uma questão insurgente, sendo importante fomentá-la com seriedade e compromisso social. Ao passo que a formação é um dos lugares que pode contribuir na constituição da identidade profissional, estabilização e consolidação da carreira docente. Assim sendo, não podemos esquecer que, a identidade docente não é fixa, imutável, tampouco um dado a priori, ela é construída nas relações de poder e saber. Segundo Pimenta (2012, p. 20):

Uma identidade profissional se constrói, pois, a partir da significação social da profissão; da revisão constante dos significados sociais da profissão; da revisão das tradições. Mas também da reafirmação de práticas consagradas culturalmente e que permanecem significativas. Práticas que persistem a inovações porque prenhes de saberes válidos às necessidades da realidade. Do confronto entre as teorias e as práticas, da análise sistemática das práticas à luz das teorias existentes, da construção de novas teorias. Constrói-se, também, pelo significado que cada professor, enquanto autor e ator, confere à atividade docente no seu cotidiano a partir de seus saberes, de seu modo de situar-se no mundo, de sua história de vida, de suas representações, de seus saberes, de suas angústias e anseios, do sentido que tem em sua vida o ser professor. Assim como a partir de sua rede de relações com outros professores, nas escolas, nos sindicatos e em outros grupos.

Quando um/a professor/a é designado a lecionar em uma escola, ele/ela traz sua história de vida, seus desejos, suas crenças, seus valores, seus medos, anseios, bem como, traz o conceito do que é ser professor/a e do que é educação. Tudo isso influencia em sua prática profissional. Vários fatores que estão envolvidos no processo de "formação", fatores bem singulares, sendo de ordem pessoal, social, cultural. Portanto, não podemos "negar" esses aspectos de "movimento social" que constitui cada sujeito (FIORENTINI, CASTRO, 2006). Não dá para indicar um "caminho certo" para a formação do/a professor/a, partimos do pressuposto que o/a professor/a precisa inventar um novo e peculiar caminho no percurso de sua formação, sendo ele/a mesmo o/a próprio/a construtor/a do conhecimento e autor/a da própria prática pedagógica.

Pautadas nesta reflexão, a gestão passou a conhecer a história de vida de cada professor/a que integra o corpo da escola, foco do Projeto de Educação Inclusiva. De posse dos dados, fez alguns encaminhamentos para a psicóloga que atende os/as estudantes municipais, pois algumas professoras se encontravam com sérios problemas pessoais e estavam desmotivadas, afetando seu trabalho em sala de aula. Além disso, a gestão buscou parcerias com profissionais da saúde, como: fisioterapeuta, massoterapeuta e educador físico para realizar atividades de meditação, relaxamento e recreação com todos/as os/as funcionários/as da escola. Esta ação tinha a periodicidade quinzenal, sendo realizadas nas sextas-feiras alternadas. Esses momentos tinham como meta provocar a integração, descontração e melhorar a autoestima da equipe escolar. No início houve resistência por parte de uma docente, que se recusou a participar desses momentos, todavia, depois de quase dois meses, a mesma externalizou o motivo de sua ausência nas atividades relatando estar se divorciando, o que impactou a sua família. Ao 
tomar conhecimento da situação, os/as demais colegas de trabalho acolheram a docente, resultando na ampla participação nas atividades propostas, bem como na indicação de outros momentos de confraternização, a exemplo de viagens em grupo.

\section{Um olhar sensível da gestão: situações-limites em foco}

Depois de conquistar a confiança dos/as funcionários/as, a meta foi direcionar o olhar para a problemática da escola. Um encontro dialógico foi marcado para provocar um olhar coletivo, observando com profundidade as situações-limites da escola. As situações-limites, segundo Freire (2003), podem ser vistas como barreiras ou como oportunidade de crescimento:

Os homens e mulheres têm várias atitudes diante dessas "situações-limites": ou as percebem como um obstáculo que não pode transpor, ou como algo que não querem transpor ou ainda como algo que sabem que existe e que precisa ser rompido e então se empenha na sua superação (FREIRE, 2003, p. 205, grifo do autor)

As situações-limites desta escola foram colocadas como meta de superação. De posse das reflexões freirianas, em uma reunião com pais, alunos, professoras e demais funcionários/as, foram listadas a situação que a escola se encontrava, a qual descrevemos no quadro abaixo:

Quadro 01 - Situações-limites da escola. Infraestrutura inadequada (escola com paredes sujas, fácil acesso de pessoas externas, banheiro sem
acessibilidade, mau cheiro do esgoto, insetos);

Alto índice de crianças e adolescentes público alvo da Educação Especial e falta de sala para atendimento educacional especializado;

Ausência de auxiliares para cuidar das crianças e adolescentes público alvo da Educação Especial

Quadro severo de violência física e verbal;

Dificuldade de leitura e escrita;

Alunos e funcionários desmotivados;

Baixo rendimento escolar;

Alto índice de evasão e reprovação;

Mobiliário da educação infantil inadequado;

Ausência das famílias e comunidade;

Transtorno quanto ao transporte dos alunos (constantes atrasos dos ônibus);

Falta de brinquedos para a Educação Infantil;

Falta de integração entre os alunos/as, funcionários/as e comunidade.

Insuficiente formação para trabalhar com as variadas deficiências;

Fonte: Dados do diálogo.

Diante de tantos problemas, em sua maioria, de responsabilidade do município, mas nada tinha sido feito até o momento, foi questionado: como provocar a participação da família e da comunidade? Como proporcionar o desenvolvimento dos alunos para 
diminuir a taxa de evasão e reprovação? Como ajudar os/as professores/as articularem a teoria e prática? Como ajudá-los na elaboração de práticas pedagógicas que favorecessem a aprendizagem dos/as alunos/as. Como acionar o poder público para reforma da escola. Ou seja, como mudar a realidade daquela escola? Foram tantas indagações e as respostas não foram encontradas a partir de fórmulas mágicas, pois sabemos que não existem; então, a alternativa foi propor uma gestão dialógica e democrática, esta trouxe a possibilidade de construir novos e peculiares caminhos para mudar a realidade da escola.

Destarte, a gestão escreveu um documento endereçado à Secretaria Municipal de Educação relatando os problemas enfrentados pela escola. Contudo, foi dito que só poderiam ajudar em alguns aspectos, como por exemplo, o mobiliário apropriado para a Educação Infantil, na disponibilidade de auxiliares para cuidar dos/as alunos/as públicos alvos da Educação Especial, na fiscalização do horário do transporte escolar e na construção de um banheiro acessível, uma vez que, a escola tinha uma criança cadeirante.

É importante destacar que a escola está localizada em bairro privilegiado no município, próximo ao centro da cidade. No entanto, mais de 90\% dos/as alunos/as são oriundos/as de bairros periféricos e fazem uso de transporte escolar. Tal situação impacta todo o trabalho desenvolvido na escola, uma vez que os horários de chegada e saída dos/as alunos/as dependem exclusivamente da pontualidade dos motoristas. O que foi resolvido pela secretaria de Educação do Município. O banheiro com acessibilidade foi construído e o mobiliário da Educação infantil comprado.

Embora, a secretaria de educação tivesse colaborado em algumas necessidades, ainda existiam outras de grande importância, tais como, a construção da sala multifuncional, disponibilidade de recursos humanos e pedagógicos, reforma da estrutura da escola, visto que se encontrava toda deteriorada, tanto a parte física quanto o mobiliário das salas.

Diante deste cenário, foi necessário adotar uma gestão participativa e dialógica para provocar o engajamento de todos/as na construção de uma escola emancipatória, e consequentemente, inclusiva. Tudo isso, exigiu uma esperança ativa, uma força motriz para mobilizar alguns dispositivos e conquistar a confiança de professores/as, pais, mães, alunos/as, a comunidade, entre outros. Foi importante, provocar a sensibilização dos/as funcionário/as da escola, para que estes/as construíssem e fomentassem a formação humana.

Os desafios enfrentados não destruíram o sonho de reformar a escola. A equipe gestora foi para as lojas que vendiam materiais de construção da cidade pedir doação de tinta, cimento, areia, brita, ferro, pincel, cal, entre outros. Logo a notícia se espalha pela cidade. Assim, a equipe foi convocada pela secretária de Educação, que comovida pela situação, buscou parceiros para doar todo material que a escola precisava para realizar a reforma. É fundamental ressaltar que houve embates entre a escola e a secretaria 
Municipal de Educação, ao saber que os/as funcionários/as estavam pedindo doações, o primeiro momento foi de severas críticas pela atitude e ameaça de processo administrativo; no segundo momento, após a apresentação da situação da escola, tanto da parte infraestrutural quanto dos índices de violência, reprovação e evasão, a partir daí, houve a compreensão e o auxílio na reforma (Só doaram material, não disponibilizaram mão de obra). Enfatizamos que não é obrigação de uma gestão escolar assumir o papel que não the cabe. A reforma de uma escola municipal é de única e exclusiva responsabilidade do poder público, representada pela pessoa do Prefeito e do Secretário/a de Educação.

Entretanto, a gestão assumiu por conta própria esse compromisso, e em um mutirão composto de pais (mães), alunos/as, funcionários/as da escola e de outras escolas e comunidade (docentes e discentes da universidade, empresários, secretária de Educação, policiais, donas de casa, entre outras categorias) doaram tempo nos finais de semana para reformar a escola. Unidos/as, construíram a sala de atendimento educacional especializado, restauraram o mobiliário, confeccionaram materiais pedagógicos para sala multifuncional, construíram uma horta e jardim, tudo isso em um período de três meses. Foi um trabalho árduo, mas gratificante. Ver a alegria das crianças em estudar num espaço limpo e organizado. Como diz Paulo Freire (2003), a educação se faz na boniteza, na esperança.

Na obra Educação na Cidade, Freire (2001) aponta que:

\begin{abstract}
Para nós, a participação não pode ser reduzida a uma pura colaboração que setores populacionais devessem e pudessem dar à administração pública. [...] Implica, por parte das classes populares, um "estar presente na História e não simplesmente nela estar representadas". Implica a participação política das classes populares através de suas representações, no nível das opções, das decisões e não só do fazer o já programado. [...] Participação popular para nós não é um slogan, mas a expressão e, ao mesmo tempo, o caminho para a realização democrática da cidade (FREIRE, 2001, p. 75).
\end{abstract}

Para o autor, tudo isso implica na abertura do diálogo com todos/as que estão inseridos/as no processo educativo, isto é, docentes, estudantes e seus responsáveis, gestão, comunidade geral. Desse modo, a autonomia tem que ser partilhada, quer dizer, o poder de decisão não está centralizado em uma pessoa ou em um lugar, mas em todos/as e de forma democrática. Acreditamos que o trabalho colaborativo é realizado a partir de objetivos comuns planejados por todos/as do grupo, que trabalham em conjunto e se apoiam mutuamente. Não há relações hierárquicas, a liderança é partilhada e os/as professores/as têm a oportunidade de avaliar seu trabalho constantemente.

\title{
Na construção de uma escola inclusiva
}

Com uma escola limpa, reformada, cheia de cores e alegria era hora de trabalhar para atender os/as estudantes público alvo da Educação Especial, assim fazer justiça cognitiva atendendo alunos/as deficientes, com transtorno Global de Desenvolvimento e altas habilidades/superdotação, além dos/as estudantes que apresentavam dificuldades 
na aprendizagem. Com essa prática, foi possível dar acesso ao conhecimento para todos/as educandos/as.

Posto isto, algumas barreiras foram superadas, dentre elas, uma formação para trabalhar numa perspectiva inclusiva. Indubitavelmente, a formação inicial é insuficiente para o/a professor/a construir os saberes necessários a fim de lecionar para alunos/as com deficiência, transtorno global do desenvolvimento e altas habilidades/superdotação. Nesse ínterim, a formação necessita ser permanente, ela ocorre nas universidades e no campo de atuação profissional, bem como, na leitura de um livro, ao assistir um filme, nos encontros pedagógicos ou nas rodas de conversas com amigos/as, colegas e familiares. Uma formação permanente não é estática, ela é um constante movimento em buscas por melhorias pessoais, profissionais e acadêmicas.

Para construir uma identidade de professor/a pesquisador/a, aquele/a que busca uma autoformação, foi criado um grupo de estudos e pesquisas em Educação Inclusiva, que contou com a participação de pais/mães, de professores/as da escola, de docentes e discentes de uma Universidade Estadual (Curso de Pedagogia) e um Universidade Federal (Curso de Psicologia). Dentre os/as funcionários/as da escola, um total de 26 (vinte e seis), composto por: 09 (nove) docentes, 03 (três) cuidadoras, 01 (um) intérprete de libras, 01 (uma) professora de Braille, 04 (quatro) vigilantes, 03 (três) cozinheiras, 03 (três) zeladoras, 02 (duas) secretárias, apenas os/as docentes, cuidadoras e intérprete participaram do grupo de estudos e pesquisas, mesmo buscando um horário que pudesse contemplar a todos/as; por motivos variados, a adesão não foi de $100 \%$ dos funcionários/as. É importante relatar que, os encontros contavam em média com a presença de 08(oito) a 12 (doze) pais/mães/responsáveis dos/as alunos/as, sendo um universo de 308 (trezentos e oito) estudantes, 83 (oitenta e três) são públicos alvos da Educação Especial, isso representa uma pequena parcela da família que se envolvia com o grupo de estudos, certamente essa baixa adesão pode estar associada ao fato da escolar ser localizada distante das residências dos/as alunos/as, dificultando assim, o acesso. Desse modo, há que se pensar em encontros nas proximidades das casas das famílias para de fato alcançar maior participação.

A partir dos diálogos estabelecidos entre gestão, família e professores/as, algumas medidas foram elencadas, as quais destacamos: investimento na formação dos/as professores/as para construir uma prática educativa crítica e estimuladora; reconstrução do projeto pedagógico da escola para diminuir o fracasso escolar; criação de duas salas para atendimento educacional especializado na própria escola, com o objetivo de ofertar a Educação Especial; realização de reuniões nos bairros onde os/as alunos/as residiam; realização de visitas domiciliares (objetivando conhecer as histórias de vida dos alunos e alunas); realização de seminários internos para refletir sobre a prática pedagógica. As reuniões nos bairros e as visitas domiciliares possibilitaram uma maior aproximação da escola com a comunidade, especialmente, porque a escola está localizada longe das 
residências dos estudantes, o que impossibilitava a participação das famílias nas reuniões escolares.

Ainda sobre a formação de professores/as, Schon (1997) apresenta uma perspectiva construída no triplo movimento da reflexão na ação, da reflexão sobre a ação e da reflexão sobre a reflexão na ação. Os seminários se constituíram como este espaço propício para reflexão, autoformação, reelaboração e revisitação dos saberes. Foi realizado um encontro intitulado "Chá inclusivo", dividido em três momentos - primeiro só com os/as professores/as, segundo com os/as responsáveis dos/as estudantes e o terceiro encontro foi constituído por toda comunidade escolar. O objetivo foi escutar e orientar na promoção da inclusão escolar.

Nóvoa (1992) aponta que este tipo de formação promove uma construção de identidade profissional autônoma, capaz de produzir o desenvolvimento da vida pessoal, profissional e organizacional de futuros professores/as. Pimenta (2012, p. 33), nos convida a pensar a formação nessa perspectiva de Nóvoa e Schon.

[...] a formação envolve um duplo processo: o de autoformação dos professores, a partir da reelaboração constante dos saberes, que realizam em sua prática, confrontando suas experiências nos contextos escolares; e o de formação nas instituições escolares em que atuam. Por isso é importante produzir a escola como espaço de trabalho e formação, o que implica gestão democrática e práticas curriculares participativas, propiciando a constituição de redes de formação contínua, cujo primeiro nível é a formação inicial (PIMENTA, 2012, p. 33).

Todavia, é necessário que o/a docente tenha tempo, espaço e oportunidade para buscar essa autoformação. Sob este prisma, além da Universidade, a escola também se configura como excelente espaço para formação docente. Uma vez que, a formação inicial por si só não é suficiente para construção dos saberes da docência. Garcia (1999) em seu livro formação de professores afirma que a "formação":

(...) estuda os processos através dos quais os professores - em formação ou em exercício - se implicam individualmente ou em equipe, em experiências de aprendizagem através das quais adquirem ou melhoram os seus conhecimentos, competências ou disposições, e que lhes permite intervir profissionalmente no desenvolvimento do seu ensino, do currículo e da escola, com o objetivo de melhorar a qualidade da educação que os alunos recebem (GARCÍA, 1999, p. 26).

A ênfase do autor na formação, sugere que o/a professor/a esteja imerso profissionalmente em um ambiente que favoreça sua formação de forma contínua e prospectiva, para mobilizar o docente na busca também pela autoformação. Esta busca tende a construir a pedagogia do amor, da esperança, do diálogo e da autonomia. Assim, romper com os modelos educacionais reprodutivistas, tecnicistas, antidialógicos, contra hegemônicos, dessa maneira, transformar a escola em um ambiente propício para aprendizagem de sujeitos populares críticos e conscientes. A propósito, Freire (2019, p 115-116) diz:

Daí que, para esta concepção como prática da liberdade, a sua dialogicidade comece, não quando o educador-educando se encontra com os educandos- 


\section{-Revista de Iniciação à Docência, v.6, n.2, 2021- Publicação: dezembro, 2021 - ISSN 2525-4332}

educadores em uma situação pedagógica, mas antes, quando aquele se pergunta em torno do que vai dialogar com estes. Esta inquietação em torno do conteúdo do diálogo é a inquietação em torno do conteúdo programático da educação.

Paulo Freire nos convida a pensar a escola e o papel do/a professor/a na formação do/a educando (as). Para Freire (2019), o papel do/a educador/a e do/a educando/a deve ser bem definido, onde todos têm a oportunidade de sistematizar, organizar, dialogar, problematizar o conhecimento, o conteúdo pragmático da educação, enfim, partindo das situações problemas, da cultura e das necessidades de todos/as.

Aqui, Freire (2019) nos convoca a dialogar com a História para quebrar as ideologias dominantes e permitir que os/as professores/as compreendam o processo de produção discursiva que oprimem em seu local de trabalho. O referido autor, enfatiza a necessidade dos cursos de formação docente possibilitarem uma análise crítica dos processos históricos para compreender os processos opressores e excludentes do presente.

No livro Pedagogia da Autonomia, ao inscrever-se na esteira dos estudos sobre a atuação docente, Freire se atenta para o cenário que trama a educação de meninos e meninas. Conclui que ensinar exige algumas posturas do professor e da professora, dentre elas, o saber ouvir, falar, respeitar às diferenças, ter coerência entre o que diz e faz, ter segurança na prática docente, ou seja, ensinar não se resume a uma simples transmissão de conhecimento, mas na entrega total em busca de novos caminhos para a prática educativa. Entretanto, é necessário priorizar a autoformação para ofertar uma educação emancipadora e autônoma do ser humano, priorizando a formação integral do/a educando/a.

Ainda sobre o autor, temos a reflexão: "Que estranha maneira é essa de fazer História, de ensinar Democracia, espancando os diferentes, para em nome da Democracia, continuar gozando da liberdade de espancar!” (FREIRE, 2020, p. 40). Não dá para viver imerso a uma prática profissional que visa manter o status quo, é preciso desestabilizar o que está posto e problematizar qualquer forma de opressão, dando lugar, sem dúvida, a uma educação libertária.

\section{Parceria entre Família e escola: relação necessária}

A escola é um espaço privilegiado para construção e movimentação de saberes de estudantes, docentes, gestores/as, pais, mães, entre outras categorias. A escola deve estar a serviço de todos/as e pensada por todos/as, uma vez que a educação é uma grande aliada na formação de identidades crítico-reflexivas. Sob essa perspectiva, a gestão planejou e executou ações que possibilitaram a aproximação da escola com as famílias e a comunidade local. Destacamos: 
Quadro 02: Ações entre escola, família e comunidade.

\begin{tabular}{|l|}
\hline Dia da família na escola \\
\hline Oficina de crochê, bordado, pintura e culinária para família \\
\hline Apresentação teatral dos/as estudantes em praças públicas \\
\hline $\begin{array}{l}\text { Aula de campo com a participação da família (visita a feira, praça, museu, parque da lagoa, aterro sanitário, } \\
\text { empresa que trata água da cidade) }\end{array}$ \\
\hline Momento de contação de histórias pela família \\
\hline Mutirão de reforma da escola \\
\hline Parceria com pais eletricistas, pintores, pedreiros para contribuir na manutenção do espaço. \\
\hline Oficina de Libras e Braille \\
\hline Momento dialógico entre os familiares e psicólogos \\
\hline Parceria com a secretaria de Saúde - palestras, oficinas (orientações na área da saúde) \\
\hline Parceria com conselho Tutelar - palestras, oficinas (orientações do direitos e deveres)
\end{tabular}

Fonte: Dados da pesquisa.

A participação das famílias nas atividades coletivas da escola foram significativas, influenciando de maneira positiva na prática do/a professor/a e no rendimento das crianças. Foi visível a satisfação da família em poder estar ali naquele espaço de formação dos filhos/as, o que trouxe mais confiança por parte dos pais/mães no trabalho do/a educador/a. Por se tratar de uma escola que atende crianças de comunidades diversas e um pouco distantes, a aproximação da família antes desse processo não era algo frequente.

O fato de buscar conhecer as realidades diversas das famílias implica também na prática pedagógica, uma vez que, Freire (2007, p. 15) afirma que "pensar certo coloca ao professor amplamente, à escola, o dever de não só respeitar os saberes com que os educandos, sobretudo os das classes populares, chegam a ela - saberes socialmente construídos na prática comunitária”. O pensar certo para Freire se refere justamente na contextualização da prática pedagógica, trazer a realidade dos/as estudantes para a sala de aula e problematizar os fatos sociais que ocorrem na comunidade local.

À medida que uma gestão dá a palavra a toda comunidade escolar, a gestão é participativa e dialógica. Indiscutivelmente, a palavra pode ser fonte inspiradora da ação e da reflexão, consequentemente, da práxis. Essa abertura, põe em movimento o diálogo tão imprescindível à existência humana. De modo geral, uma gestão que elege os princípios fundantes do pensamento freiriano busca na abertura do diálogo a base de 
suas práticas, respeita as múltiplas opiniões e estabelece parcerias profícuas. Para melhor análise dos impactos dessa gestão freiriana, apresentamos os dados no quadro a seguir, referentes aos anos de 2015 a 2019:

Quadro 03: Taxa de reprovação.

\begin{tabular}{|l|l|l|l|l|l|}
\hline Seguimento & 2015 & 2016 & 2017 & 2018 & 2019 \\
\hline $1^{\circ}$ ano & $1,0 \%$ & $0,0 \%$ & $0,0 \%$ & $0,0 \%$ & $0,0 \%$ \\
\hline $2^{\circ}$ ano & $2,3 \%$ & $1,7 \%$ & $0,0 \%$ & $0,0 \%$ & $0,0 \%$ \\
\hline $3^{\circ}$ ano & $38 \%$ & $30 \%$ & $28 \%$ & $22 \%$ & $20,0 \%$ \\
\hline $4^{\circ}$ ano & $35,2 \%$ & $25 \%$ & $20 \%$ & $18 \%$ & $16,4 \%$ \\
\hline $5^{\circ}$ ano & $30 \%$ & $3,5 \%$ & $2,8 \%$ & $1,5 \%$ & $0,0 \%$ \\
\hline
\end{tabular}

Fonte: Dados da pesquisa.

Os dados revelam que uma gestão participativa refletiu positivamente nas taxas de aprovação que subiram no $1^{\circ}, 2^{\circ}$ e $5^{\circ}$ ano para $100 \%$, do $3^{\circ}$ ano para $80 \%$ e do $4^{\circ}$ ano para 83,6\%. A taxa de evasão caiu para 0,3\%, visto que em 2014 era de 26,4\%. O índice de atestados médicos e licenças médicas dos/as professores/as e funcionários/as diminuíram, posto que anterior ao ano de 2015, em média havia uma quantidade regular de 1 (um) a 2 (dois) atestados mensalmente, bem como o afastamento de uma docente por licença médica. Destarte, há seis anos, os atestados médicos têm sido esporádicos, caindo para uma média de 2 (dois) por ano. Evidentemente, houve mudanças profundas no comportamento, assiduidade, pontualidade e rendimentos dos alunos/as, ao passo que: diminuiu significativamente os episódios de violência dentro da escola; - as aulas de reforço escolar para os/as alunos/s com dificuldades de aprendizagem refletiram no maior aproveitamento dos estudos na classe regular; - o atendimento educacional especializado para os estudantes públicos alvos da Educação Especial contribuiu para o melhor desenvolvimento destes/as; - os motoristas dos ônibus prezam pela pontualidade; entre outros mais.

\section{Considerações finais}

Sabemos que o/a professor/a é um dos/as personagens centrais e mais importante na disseminação do conhecimento e de elementos substanciais da cultura, ou seja, é necessário, sobretudo, oferecer ideias, reflexões e questionamentos que o/a estimule no debate sobre a sua formação e a busca pela autoformação constante. Dessa maneira, é importante oferecer-Ihes condições favoráveis para o desenvolvimento de práticas emancipatórias

Pensar na formação de professores/as na atualidade brasileira nos remete a refletir sobre os diversos âmbitos que esta questão traz, olhar a história de vida do/a 
professor/a, a relação que este/a estabelece com a escola, as condições de seu trabalho oferecida, suas necessidades formativas, o plano de carreira, etc. Tudo isso é de grande importância para valorizar o profissional docente e assegurar as condições adequadas de trabalho.

Em síntese, na coletividade buscar caminhos que promovam a valorização docente, de maneira a ofertar um ambiente propício para a prática educativa. O/a gestor/a é de suma importância neste aspecto, pois ele/ela pode provocar um trabalho pautado na colaboração para que cada sujeito envolvido no processo, assuma um papel autônomo e busque condições para que a Educação aconteça de forma satisfatória. A referida escola tornou-se referência no município, particularmente, pelo trabalho inclusivo ofertado, sendo reconhecida como a "Escola Inclusiva", recebendo uma homenagem em cerimônia pública, na Câmara de Vereadores/as.

Em um ato político, toda comunidade contribuiu para mudanças qualitativas na educação ofertada, desde reparo de carteiras e cadeiras, construção de hortas e jardins, confecção de materiais pedagógicos, bem como a reforma da escola, tornando-a acessível a todos/as. Educação de qualidade é possível com o engajamento de todos/as, sendo que, o/a professor/a é um sujeito essencial dessas mudanças e carece de todos os cuidados no âmbito pessoal e profissional.

Esse entendimento, nos leva a refletir que um docente feliz no trabalho, que gosta de sua profissão, tende a desenvolver um excelente trabalho pedagógico. Portanto, a escola necessita ser gerida por um/a profissional que contribua na construção e organização de um espaço propício para o desenvolvimento de estudantes e professores/as.

É preciso reconhecer que uma gestão democrática, participativa e dialógica não se faz de forma isolada. Seria ingênuo fechar uma gestão na percepção e atuação de uma única pessoa. Um/a gestor/a necessita do constante apoio de toda comunidade escolar, para promover uma educação de qualidade - emancipatória e libertária. Então, uma gestão freiriana está aberta para o diálogo, não teme o novo, se permite conhecer a realidade para poder intervir nela, dito de outro modo, uma gestão freiriana busca uma formação permanente para si e para os/as outros/as, situando-se no e com o mundo, sobretudo, tem compromisso ético com a educação.

A gestão relatada neste artigo, foi uma inspiração para muitas outras escolas, ao passo que, foi criada uma rede solidária de gestão itinerante para desenvolver algumas práticas exitosas em outros espaços educativos, a exemplo da reforma da estrutura física e o desenvolvimento de projetos para combater a violência escolar. É importante relatar que houve alguns desafios para assumir uma gestão democrática freiriana, dentre os quais destacamos: - contar com o efetivo apoio da Secretaria Municipal de Educação, particularmente para realizar a reforma da escola (fornecer material e mão de obra) e disponibilizar recursos humanos, a exemplo de uma quantidade maior de cuidadores/as 
para os/a alunos/as com deficiência ou com transtorno global do desenvolvimento (autismo), visto que o total de 03 profissionais não foram o suficiente para suprir as necessidades da escola; - dificuldades de aproximação com as famílias devido à localização geográfica da escola, por ficar situada distante das residências dos/as estudantes; - contar com a participação dos/as funcionários/as, como os vigilantes, as cozinheiras, as zeladoras e os/as secretário/as nos grupos de estudos, pois entendemos que os encontros do grupo de estudo e pesquisa, além de ser um espaço de aprendizagem, constitui também um lugar de estreitamento de laços afetivos; estabelecer parcerias com a secretaria municipal de saúde para atender o público alvo da educação especial, alguns estudantes necessitaram de laudo médico, contudo, não conseguimos atendimento para todos/as.

É essencial salientar que, as ações realizadas e o sucesso delas, não isenta a responsabilidade dos governantes de cumprir com as obrigações e oferecer uma educação de qualidade para todos/as; tendo em vista que nada tinha sido realizado para melhorar a situação difícil em que se encontrava a escola, por parte do município. Observamos a necessidade de políticas públicas educacionais locais direcionadas para os problemas que as escolas ainda apresentam, como o estabelecimento de parcerias com as universidades públicas para fomentar a formação continuada de professores/as, criar constantes reuniões entre gestores/as municipais e as escolas de Educação Básica pública, para conhecer e traçar ações de melhoria desses espaços; disponibilizar profissionais de saúde mental para atendimento de alunos/as e funcionários/as de forma em geral. Este estudo não esgota a discussão, mas por ora, dá espaço para pensarmos na gestão escolar freiriana como um lugar de movimentação de ações que pode favorecer alunos/as e seus familiares, profissionais da educação e comunidade em geral. Desse modo, é necessário provocar o envolvimento de todos/as a partir do desenvolvimento de uma gestão colaborativa.

\section{Referências}

ALARCÃO, Isabel. Professores reflexivos em uma escola reflexiva. São Paulo: Cortez, 2003.

CONTRERAS, José. A autonomia de professores. São Paulo: Cortez, 2002.

FIORENTINI, Dário.; LORENZATO, Sérgio. Investigação em Educação Matemática: percursos teóricos e metodológicos. Campinas, SP: Autores Associados, 2006.

FREIRE, Paulo. A Educação na Cidade. 7.ed. São Paulo: Cortez, 2001.

FREIRE, Paulo. Pedagogia da Esperança: um reencontro com a Pedagogia do Oprimido. 10 ${ }^{\mathrm{a}}$ ed. Rio de Janeiro: Paz e Terra, 2003.

FREIRE, Paulo. Pedagogia da autonomia: saberes necessários à prática educativa. São Paulo: Paz e Terra, 2007. 
FREIRE, Paulo. Pedagogia do Oprimido. $69^{\text {a }}$ ed. Rio de Janeiro/São Paulo: Paz e Terra, 2019 .

FREIRE, Paulo. Educação e política. Organização: Ana Maria de Araújo Freire. 5. ed. Rio de Janeiro/São Paulo: Paz e Terra, 2020.

GARCÍA, Carlos Marcelo. Formação de Professores: para uma mudança educativa. Porto, Portugal: Editora Porto, 1999.

IMBERNÓN, Francisco. Formação docente e profissional: formar-se para a mudança e a incerteza. 9. ed. São Paulo: Cortez, 2011.

LÚDKE, Menga; ANDRÉ, Marli Eliza Dalmazo Afonso de. Pesquisa em Educação. Abordagens qualitativas. São Paulo: EPU, 1986.

NÓVOA, António. Formação de professores e profissão docente. In NÓVOA, António. Os Professores e a sua formação. Lisboa: Instituto de Inovação Educacional, 1992

PIMENTA, Selma Garrido. Saberes pedagógicos e atividade docente. $8^{\text {a }}$ ed. São Paulo: Cortez Editora, 2012.

PIMENTA, Selma Garrido; GHEDIN, Evandro (org.). Professor reflexivo no Brasil: gênese e crítica de um conceito. São Paulo: Cortez, 2002.

SCHÖN, Donald. Formar professores como profissionais reflexivos. In: NÓVOA, A. (Org.). Os professores e a sua formação. 3. ed. Lisboa: Dom Quixote, 1997.

TARDIF, Maurice. Saberes docentes e formação profissional. 3. ed. Petrópolis, RJ: Vozes, 2002.

Recebido: 26.08 .2021

Aprovado: 06.12.2021 